\title{
ONLINE UNIVERSITY ORIENTATION MODELS FOR STUDENT TRANSITION BETWEEN SECONDARY AND TERTIARY EDUCATION
}

\author{
Francesco Floris ${ }^{1}$, Marina Marchisio ${ }^{1}$, Matteo Sacchet ${ }^{1}$, Tiziana Margaria ${ }^{2}$ and Sergio Rabellino ${ }^{3}$ \\ ${ }^{1}$ Department of Molecular Biotechnology and Health Sciences, University of Turin, Via Nizza 52, 10126 Turin, Italy \\ ${ }^{2}$ Department of Computer Science and Information Systems, University of Limerick, Lero, the Irish Software Research \\ Centre, Tierney Building, V94 T9PX Limerick, Ireland \\ ${ }^{3}$ Department of Computer Science, University of Turin, C.so Svizzera 185, 10149 Turin, Italy
}

\begin{abstract}
The transformation of higher education practices needs to be accompanied by the deployment of university guidance. This is especially important when activities have to be carried online and remotely. Online students expect to receive precise information to be successful learners, just as they would if they were in a face-to-face setting, but even more, due to the large capabilities of digital services. Worldwide universities provide free and open access to educational content online, but this is effective for guidance only if it is the main objective of courses and resources. One way to address student transition has been experimented by the University of Turin with the action Orient@mente that helps students in their transition from secondary school to university. In Orient @ mente, students can find useful information, guidance activities, automatically graded tests to prepare for university admittance, online courses for revising basic knowledge, resources for foreign students, and information about the Erasmus program. This action has already proven its usefulness and it is expanding as a transversal and international model. Soon a new action will be fully developed, Eirenteering, a name mixing Eire (the Irish name for Ireland) and Orienteering. This paper discusses the methodologies adopted in Orient@mente and the forthcoming Eirenteering, together with results obtained with Orient@mente concerning the usage and the usefulness of the service.
\end{abstract}

\section{KEYWORDS}

Digital Learning Environment, Online Orientation, Secondary to Tertiary Transition, University Admittance, University Guidance, University Orientation

\section{INTRODUCTION}

The transformation of higher education practices generates new challenges for university guidance. Many changes arose after the Bologna process, a series of ministerial meetings aimed at bringing more coherence to higher education systems across Europe and at making higher education more inclusive, accessible, attractive, and competitive worldwide. The Bologna Follow Up Group has identified three key commitments: the implementation of the three-cycle degree structure, the recognition of qualifications, and quality assurance (European Commission/EACEA/Eurydice, 2018). Beyond these three commitments, we can find other areas of intervention, such as Opening higher education, which deals with education barriers, disadvantaged students, difficulties in completing higher education, and dropout rates. In this framework, student transition to university is an area leading to ongoing challenges that different stakeholders in institutions need to face. The transition between secondary school and the university very often occurs over a difficult time frame. The challenges in this phase are still unclear (Gueudet, 2008), both in STEM and in other disciplines. Possible barriers to study success are individual, social, due to the education system, or to personal conditions. Students need to feel accompanied in their educational path. After the enrolment, universities usually register many changes of course and abandonment of studies. Dedicated staff should help students in their orientation. Results demonstrated that having a designated office for orientation programs is important for narrowing the academic learning gap between new first-year and transfer students (Mayewh et al., 2010). Institutions try to make orientation a more personalized experience for new students by offering small orientation sessions, making 
them feel comfortable and connected to both their orientation leader and their peers in the group (Mayewh et al., 2010). In today's educational environments, the use of web-based technologies emerged, with a focus on online course delivery. In this way, orientation activities can take place even remotely and using online courses, tests, and other interactive resources (Barana et al., 2017a; Barana et al., 2017b). This is especially important in times of forced online activity (Alperin et al., 2020), not just for students, but also for working professionals. Online students expect to receive information that will prepare them to be successful learners, just as they would if they were in a face-to-face setting. When supported by institutions, new technologies can be effective for university guidance. Worldwide universities provide free and open access to educational content online. Resources, learning plans, and activities specifically designed for this objective can enhance the effectiveness of online students' guidance. Multimedia, interactive resources, automatic online assessment, Massive Open Online Courses, and the variety of tools integrated into Learning Management Systems allow institutions to contact students, to guide and to connect experts and learners. Online orientation is even more important in times of pandemic, as experienced in 2020 due to Covid-19 when different nations faced lockdown of many educational activities. New funds will be injected in the university system in Italy from the PNRR, the National Plan for Resistance and Resilience, to promote access to university, make the transition easier and faster and strengthen guidance tools in the choice of the university path.

One way to address student transition is by introducing an appropriate form of automatic formative assessment: if well-structured and provided within a proper support environment, it can improve consciousness, self-awareness, confidence, and student experience. Since 2014, the University of Turin has been supporting Orient@mente, an action to help students in the transition from secondary school to university, able to adapt to the specific needs of each student and to encourage them to choose consciously their academic studies using Open Online Courses hosted on a custom Moodle platform. Along with specific discipline contents, students can find various information, guidance activities for courses, preparation tests for university admittance, online courses for revising basic knowledge, resources for foreign students, and advices about the Erasmus program.

Online orientation can easily become international, and a model similar to Orient@mente is going to be developed soon with Eirenteering, a name mixing Eire (the Irish name for Ireland) and Orienteering. In this case, the starting point is Computer Science, since many first-year students are not sufficiently aware of the challenges intrinsic to the specific discipline (such as programming and model-driven design), related topics (such as discrete mathematics), and innovative approaches (such as formative assessment) to guide students through a resolution process whenever they have a gap in their knowledge. Eirenteering, whenever possible, will also support blended courses, because many online contents overlap with first-year modules in the common entry in Computer Science LM121 BSc.

This paper discusses the methodologies adopted and the results obtained in Orient@mente. It will also describe how this model is going to be implemented in the Irish context. After presenting the state of the art of online models for orientation in Section 2, the paper describes the research question and the methodology in Section 3. Section 4 delineates the framework in which these activities have been carried out. The model is fully analyzed in Section 5, while Section 6 reports some results concerning student online activity.

\section{STATE OF THE ART}

In education, the term guidance is used in the context of lifelong learning, career guidance, counseling, related services that support students, and specific provision of teaching and learning (Hounsell et al., 2008). University teaching can provide students with tools and skills that will help them face their future studies and career (Marchisio et al., 2020). In (Chiteng Kot, 2014), the students who made use of the centralized academic advising reported an increase in their first-term, second-term, and first-year cumulative Grade Point Average. Moreover, students who used centralized advising during the second term experienced a decrease in their probability of first-year attrition. Different studies agree with this research. In (Skaniakos et al., 2019), with self-assessed students' surveys, the authors found that general study guidance is a strong predictor of students' development of academic and generic skills, promoting also working life orientation. This is valid across all different disciplines, with some variation on the impact according to the Department.

In (Sun and Yuen, 2012) the authors discuss the adoption in China of orientation models that have been developed and mainly used in Europe or the US. The authors discuss the content, the implementation, the problems that arose, and ways of improving the university actions in China. They underline the importance of 
local factors such as the job market, the employment system, the educational philosophy, and the social value system. They propose different steps to achieve the objective of a good orientation: the construction of a student talent database, more participatory and with interactive forms of career guidance, and the establishment of a team of teachers with relevant expertise relevant for college students.

From the point of view of online orientation activities, one of the main issues is the ability to build digital capacity at a large scale. For example, according to the European frameworks, the DigComp 2.1 (Carretero et al., 2019) identifies five areas of digital competence as key components: Information and data literacy, Communication and collaboration, Digital content creation, Safety, and Problem solving. All these features are essential to the success of online activities. The Digital Education Action Plan (DEAP, 2020) deals with digital competencies, too. The communications report state the needs of a vast and growing array of digital technologies together with digital competencies for all learners. In (Herridge et al., 2020), findings suggest that students who attend online out-of-class orientation activities were more likely to become engaged in group study and preparation, having more knowledge of the institutional and academic advising support. The authors identified four recommendations for practitioners: Orientation programming should continue to enhance efforts related to student knowledge of institutional support; Practitioners should be innovative in how they construct orientation programming whether online or in traditional settings; Advising support should be central to online and traditional orientation; Institutions should engage in more critical evaluation of orientation programming; Online orientation can make use of new technologies in ICT, like artificial intelligence techniques. In (Kai et al., 2017), the authors made use of machine learning methods in order to develop prediction models to assess the effectiveness of an online orientation course in improving student retention in an online college program.

To summarize what emerged from a literature review on orientation models, various forms of orientation activities can take place. The ones coming from a centralized institutional division can be more efficient. Moreover, online orientation proved its usefulness. These are the main ingredients for the recipe of the orientation support model developed by the University of Turin and adopted by other international universities.

\section{RESEARCH QUESTION AND METHODOLOGY}

The question that motivated this research is the following: how can institutions set up an orientation process to guide students to achieve better outcomes in their university path? To understand this, we analyzed the model developed by the University of Turin with the action Orient@mente, which was recently adopted by the University of Limerick with the action Eirenteering. First, we are going to describe the framework in which those actions took place, also taking into account different indicators: Accessibility, Adaptability, Availability, Consistency, Control, Digital Environment, Open Access, Staff training, Support and communication, Sustainability. These indicators are compliant with a model of student orientation and with previous work by the research group on this topic (Barana et al., 2017a; Barana et al., 2017b). Second, we are going to present statistics from the student population of the University of Turin, especially in comparison with the usage of Orient@mente. We will underline the kind of users that interact with the online environment.

\section{THE FRAMEWORK}

A net is stronger when the strings are tightly woven together. The same applies to networks of collaboration, and this is why many universities create connections. In our specific context, we describe a growing partnership network that spans heterogeneous and interdisciplinary partners:

- the Department of Computer Science and the Department of Molecular Biotechnologies and Health Sciences (DMBHS) of the University of Turin, Italy;

- the Department of Computer Science and Information Systems (CSIS) of the University of Limerick, Ireland, as well as two national research centers: Lero - the Irish Software Research Centre and Confirm - the Smart Manufacturing Research Centre.

The main topic of the partnership is the transition between secondary and tertiary education. This is addressed with online resources and paths, openly available to students. The University of Turin (UNITO) has a long-lasting experience in the use of Digital Learning Environments (DLE), with the adoption of the Moodle platform since 2003 and its large-scale adoption for blended teaching and online projects. One of these projects, 
called “Orient@mente” (Barana et al., 2017a; Barana et al. 2017b), is aimed at encouraging students to make a more conscious and informed decision about the choice of their university studies. UNITO reinforces classic orientation activities for incoming students through a model involving interactive guidance to courses, testing with automatic evaluation, and online tutoring. The action of Orient@ mente have reinforced actual orientation activities, shared tools, and data with the pre-existing ICT services of the University. Orient@mente offers a growing number of Open Online Courses (OOCs) containing information and guidance activities for university courses, free admission tests, courses for revising basic high school knowledge, and specific resources for foreign students and Erasmus students. The adopted model is an example of mutual entailment between the academic world and social networking: students are guided to face their academic decisions, while the University monitors their progress, provides feedback about their current abilities, and tries to meet their information and self-assessment needs. This model was shown to be useful for Italian students (Floris et al., 2020). Other actions that have been carried out inside Orient@mente concern a disciplinary formative orientation, with programs that let student discover specific topics and their relation with other subjects. There is also a series of actions devoted to teachers, a course to train University Ambassadors, close guide for students.

The University of Limerick (UL) requires similar - potentially adapted - initiatives, since many first-year Computer Science (CS) students are not sufficiently aware of the specific challenges related to the discipline. For example, surveys of first-year CS students in the LM121 BSc Hons program show that only $50 \%$ of them have previous programming experience. Studies about programs in CS education (McInerney et al., 2017) show that there is a gender difference in CS and STEM education. An internal analysis in UL has shown that success is not gender-related in first-year CS, while the transition from secondary to tertiary education is one of the possible causes for the high attrition in year one. Success in the first year is essential to a positive student experience, which is a pivotal aim both in the specific UL setting and at the Irish national level. For example, the National Forum Strategic Priorities (Strategy 2019-2021) and the Third Level Computing Forum work in this direction. On the ground, the special orientation and mentorship for incoming students are addressed in UL in general by assigning faculty as personal mentors to each student. Specifically, in CS, the first-year LM121 students are additionally peer-mentored by second-year volunteers students in the CSIS-CTL co-led pilot intervention project "Making the Leap: a Pathway to Success", now in its third year. The collaboration is between the CSIS Department and the Centre for Teaching and Learning in Computer Science, which "support and promote active learning among the students of ICT related programs in UL, via the use of proven learner support approaches, tutoring innovation, research, and evaluation, to develop learners who are confident and effective ICT practitioners." So far, there is no self-assessment offer for students and prospective students.

The model of Orient@mente and, consequently, Eirenteering, provides different features.

- Accessibility. Developed contents are possibly accessible. Moreover, the platforms adopt system-wide the high-legibility font "EasyReading" designed for people with dyslexia.

- Adaptability. The model, structure, and tools can be applied to different university requirements, various disciplinary areas (as of 2020, Orient@mente lets students explore almost the entire offer of the University of Turin) and different students' learning approaches.

- Availability. From the point of view of time, both actions operate as continual services to let students access anytime. From the point of view of space, learners from all over the world can benefit from materials.

- Consistency. The platform that students navigate is the same technology that supports university modules and is adopted by many universities around the world. Students become familiar with a system that they will meet continuously throughout their careers. Moreover, the integration of multiple kinds of resources facilitates ongoing research on new technology.

- Control. Institutions and related stakeholders perform periodical analysis to understand the learning behavior of students and provide possible improvements to the action, adapting it to students' needs.

- DLE with integrated tools. The online provision of contents allows the integration with different tools with a Learning Management System (LMS), such as an Advanced Computing Environment (ACE) useful for students of STEM disciplines that require a scientific approach, and an Automatic Assessment Systems (AAS) to monitor students' results and give proper feedback whenever possible. Students are facilitated in autonomously overcoming their insecurities by immediate feedback.

- Open Access. There is no cost in accessing the online resources. This is in line with the Open Educational Resources (OER) paradigm. Moreover, when accessing the platform for the first time, 
users must accept the privacy policy that specifies their own rights about personal data, according to the European General Data Protection Regulation.

- Staff training and teamwork. Different actors were involved in the design and implementation of online contents: university professors, graduate students, $\mathrm{PhDs}$, and students with master's degrees. All these people attended a training course in the use of digital tools and online learning methodologies, coordinated by expert instructional designers and by university module leaders. Thus, highly qualified staff designed the point of contact between students and the university.

- Support and communication. The platforms link to the main source of information, which lies in the official university web pages, creating synergy with other orientation activities. Moreover, the collaboration with Regional School offices plays an essential role in promoting the actions.

- Sustainability. Students pay nothing to access the service. The university sustains all the costs for the production of materials and services, as well as the costs for recruiting staff.

Different kinds of students can fruitfully use these actions.

- Secondary school students, who are the main target of these actions and need to make informed choices at the time of enrolment.

- University students, who need to fulfil a supplementary educational obligation (for example, those who score poorly in admission tests).

- Secondary school teachers, who can count on an up-to-date environment with online contents and provide accurate suggestions to their students.

Table 1 . Needs of students in transition between secondary and tertiary education and strategies adopted by Orient@mente and Eirenteering

\begin{tabular}{|c|c|c|}
\hline Need & Orient@mente & Eirenteering \\
\hline Recover gaps in the & Realignment courses in scientific & Most secondary students do not study \\
\hline knowledge & disciplines & $\begin{array}{l}\text { Computer Science, first-year modules are } \\
\text { introductory courses }\end{array}$ \\
\hline Attend university modules & $\begin{array}{l}\text { This is done by start@ unito, another } \\
\text { action of UNITO }\end{array}$ & $\begin{array}{l}\text { First-year open online courses in Computer } \\
\text { Science }\end{array}$ \\
\hline Prepare for admission tests & $\begin{array}{l}\text { Test area, plus an area dedicated to medical } \\
\text { sciences and healthcare professions }\end{array}$ & $\begin{array}{l}\text { There is no admission test in Computer } \\
\text { Science }\end{array}$ \\
\hline Explore degree programs & $\begin{array}{l}\text { Area to explore almost all degree programs } \\
\text { at UNITO }\end{array}$ & $\begin{array}{l}\text { Students can explore Computer Science } \\
\text { Common Entry }\end{array}$ \\
\hline
\end{tabular}

To summarize, these actions answer to some of the needs of students that triggered a response from the university. In Table 1, we summarize some of these needs and highlight the answer given by each action. As stated in the table, some of the students' needs in the transition to university are provided by other actions, too. As an example, at UNITO there is also start@unito, a platform that delivers 50 open online courses prepared specifically for students who are attending a university module for the first time (Bruschi et al., 2018; Marchisio et al., 2019).

\section{RESULTS}

In this section, we are going to report subscriptions, logins, and other data collected from platform usage to give an idea of the action Orient@ mente. The data were collected in July 2021. The platform hosts 69,398 users, $11 \%$ of which are students at UNITO (7888 users) because they use the institutional student email address. In all the other cases, the detection of the correspondence between UNITO students and Orient@mente users is not straightforward, because the only identifier in joining the two datasets is represented by the email address, and the same person may use multiple accounts. Open access sometimes means difficulties in joining with other data sources.

To understand the impact of Orient@mente, we performed a comparison between users' subscriptions and the number of first-year students at UNITO. The numbers are shown in Table 2. The size of the numbers is comparable. The number of first-year students has increased across the years, while the number of Orient@mente users has initially grown, and then slightly decreased. 
Table 2. Yearly new subscriptions to Orient@mente compared with UNITO first-year students

\begin{tabular}{llll}
\hline Year & $\begin{array}{l}\text { Orient @ mente } \\
\text { subscriptions }\end{array}$ & UNITO first-year students & Ratio \\
\hline 2015 & 4,307 & 17,800 (Academic Year 2014/2015) & $24 \%$ \\
2016 & 6,613 & 18,500 (Academic Year 2015/2016) & $36 \%$ \\
2017 & 11,358 & 20,800 (Academic Year 2016/2017) & $55 \%$ \\
2018 & 17,270 & 22,400 (Academic Year 2017/2018) & $77 \%$ \\
2019 & 15,693 & 23,100 (Academic Year 2018/2019) & $68 \%$ \\
2020 & 11,119 & 23,600 (Academic Year 2019/2020) & $47 \%$ \\
2021 & 7,552 & 26,000 (Academic Year 2020/2021) & $29 \%$ \\
\hline
\end{tabular}

Orient@mente alone does not equal the numbers of all first-year students, but on average around $48 \%$ of first-year students made use of the support, which is quite an interesting result.

As explained in the previous sections, students can navigate into different areas: Area 1, online courses to recover gaps in the knowledge and fulfil additional education duties (17,479 subscriptions), Area 2, courses devoted to exploring the degree programs at the University of Turin (22,886 subscriptions), Area 3, courses to prepare for admission tests (83,554 subscriptions), and a new specific area (Area 4) for admission tests in medical sciences and healthcare professions (1,408 subscriptions). Moreover, the platform devoted another area for the TARM test, Assessment Test of Minimum Requirements, which was delivered by Orient@mente. This area is now no longer supported (18,247 subscriptions) because the university decided to ask an external agency to organize the TARM and the admission test.

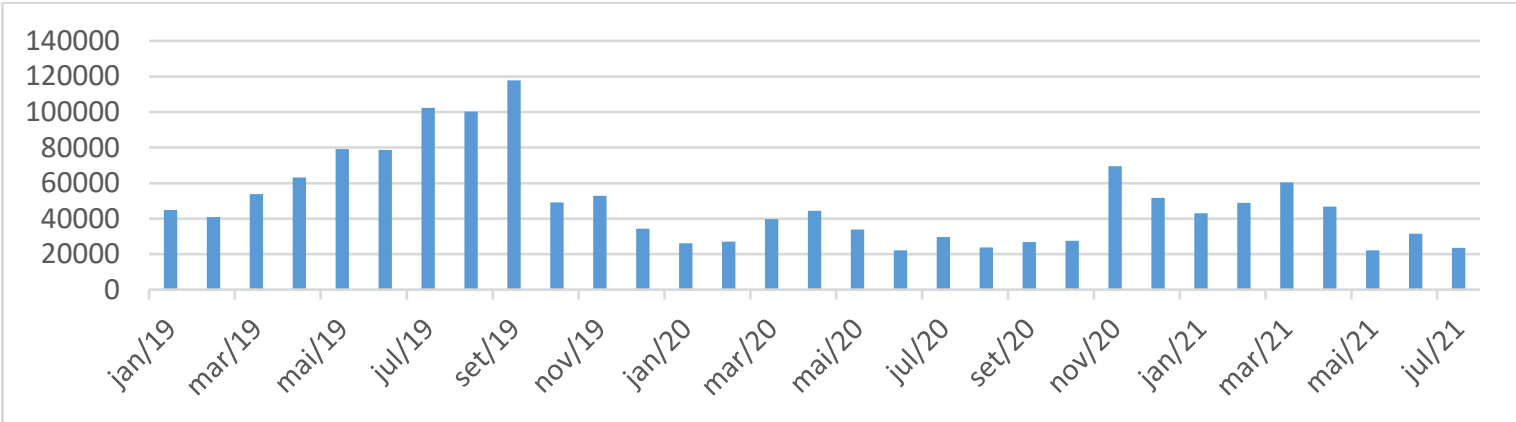

Figure 1. Number of user logins in Orient@ mente divided by month from January 2019 to July 2021

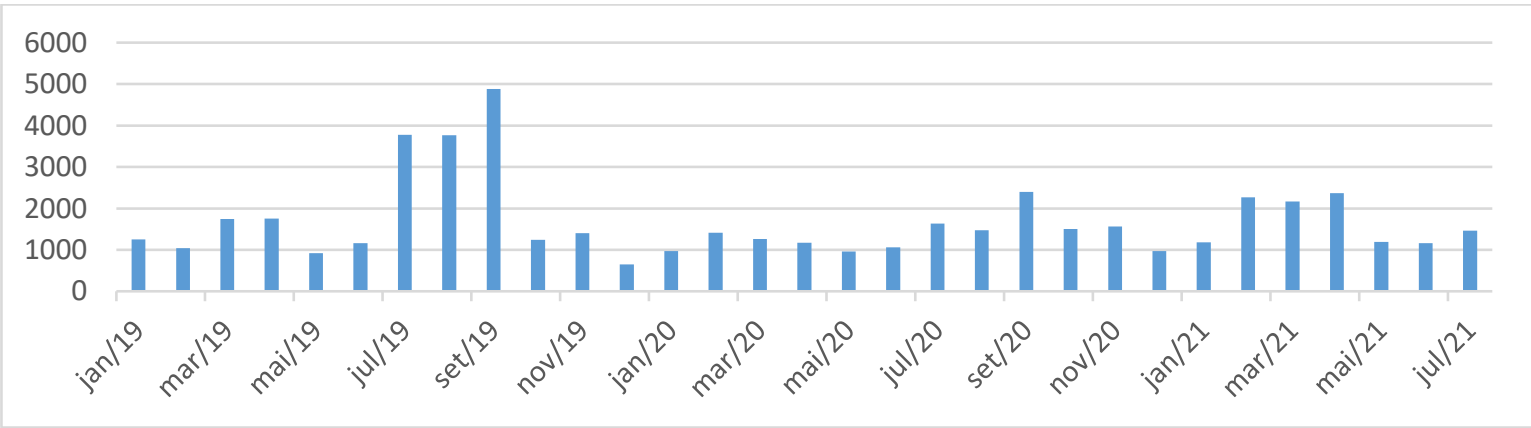

Figure 2. Number of unique user logins in Orient@ mente divided by month from January 2019 to October 2020

Figure 1 considers the number of user logins. In the period January 2019-July 2021, the average number of monthly student logins was 48,857 . On the other side, Figure 2 considers the number of distinct user logins. In the period January 2019-July 2021, the average number of monthly student distinct logins was 1,670 . The numbers suggest that many students use the online platform, even though the numbers are not increasing over time. This depends also on actions that are carried out by the university and the project managers: when there is something new in the platform, there is an advertisement and more users subscribe. 
The time that students spend surfing the platform can vary significantly. It is worth noting that half of users subscribed and viewed contents just for one day (54.5\%). This is quite reasonable for students who simply wish to explore the various degree programs or attempt the admission tests just once successfully. Excluding users that subscribed and viewed the platform just for one day, the time difference between the first and the last access is on average 133 days. This number is more related to students who attend the online courses to remediate gaps in their knowledge, in fact 116 days is a suitable time for studying.

\section{CONCLUSION}

There are different objectives behind the improvements in the organization of university's orientation actions: facilitate students' transition between different education systems, prevent the dropout in the study program, and improve students' responsibility towards their academic studies. The present paper fully describes and explains the setup of the orientation processes. The model provides different features that all together lead to a positive and fruitful experience. Furthermore, it is applicable and sharable among different universities.

The adaptive learning path containing the remedial procedure created to assess and fill learning gaps in Computer Science does indeed retain the features of the University of Turin model and the related literature. The features acted as a guideline in designing new learning paths.

The actions are alive and continuously developing. On one side, Orient@mente in 2020 has extended the number of interactive paths to all courses at the University of Turin. Even the test area was expanded, with numerous activities to prepare admission tests to medical degrees, which are, in Italy, very restrictive. On the other side, Eirenteering is still in its infancy, with two interactive first-year modules in Computer Science. More online resources are currently under development, in particular in collaboration with the team of ISE, the new integrated BSc/MSc Immersive Software Engineering that will start in Limerick in September 2022. Future work in Eirenteering concerns the development and delivery of adaptive assessments in an open online learning environment. Considering the most up-to-date trends in education (openness, mobile learning, adaptive learning, etc.), the platform contents provide individual orientation to prospective first-year students and help them consciously make their choice about an academic career in Computer Science. This way, prospective students will test their skills and competencies for the first time in advance of their application, while evaluating different possible career paths. This new opportunity will also directly affect students that have difficulties in attending classes, such as working students or students with limited mobility. Learning Analytics create new opportunities for student orientation, delivering early warnings that alert teachers, instructors, and students when there is a risk of not meeting academic goals, especially for people who often work directly with students, but usually not in classroom settings, like academic advisors in higher education and other professionals in the K-12 system (Ocumpaugh et al., 2017). Data collection analysis and learning analytics techniques (Marchisio et al., 2019) applied to the fine granular data obtained from the online platform is likely to provide new insights into how students learn on their own time, thus helping us to improve teaching and learning in Computer Science.

\section{ACKNOWLEDGEMENT}

This research was funded, from the Orient@mente side, by the bank foundation "Compagnia di San Paolo". From the Eirenteering side, the research was funded by the Science Foundation Ireland grant 13/RC/2094 by Lero - the Irish Software Research Centre (www.lero.ie), HEA/NF SATLE 2019 Funding from the Irish National Forum for the Enhancement of Teaching and Learning in Higher Education. 


\section{REFERENCES}

Alperin, L. et al., 2020. The Role of Orientation Programs to Prepare Students for Online Learning: A Case Study from an Executive MPH Program. Pedagogy in Health Promotion, 6(4), pp. 239-245. doi:10.1177/2373379920953375

Barana, A. et al., 2017a. Open platform of self-paced MOOCs for the continual improvement of academic guidance and knowledge strengthening in tertiary education. Journal of e-Learning and Knowledge Society, 13(3), pp. 109-119. doi:10.20368/1971-8829/1383

Barana, A. et al., 2017b. Self-paced approach in synergistic model for supporting and testing students: the transition from Secondary School to University. Proceedings of 2017 IEEE 41st Annual Computer Software and Applications Conference (COMPSAC). Torino, Italy, pp.404-409. doi:10.1109/COMPSAC.2017.211

Bruschi, B. et al., 2018. Start@unito: a Supporting Model for High School Students Enrolling to University. Proceedings of the international conference on Cognition and Exploratory Learning in Digital Age (CELDA 2018), Budapest, Hungary, pp. 307-312.

Carretero, S. et al., 2017. DigComp 2.1: The Digital Competence Framework for Citizens with eight proficiency levels and examples of use. EUR $28558 E N$. doi:10.2760/38842

Chiteng Kot, F., 2014. The Impact of Centralized Advising on First-Year Academic Performance and Second-Year Enrollment Behavior, Res High Educ 55, pp. 527-563. doi:10.1007/s11162-013-9325-4

DEAP, 2020. Digital Education Action Plan 2021-2027 - Communication September 2020, retrieved from https://ec.europa.eu/education/sites/default/files/document-library-docs/deap-communication-sept2020_en.pdf, last accessed July29th, 2021.

European Commission/EACEA/Eurydice, 2018. The European Higher Education Area in 2018: Bologna Process Implementation Report. Luxembourg: Publications Office of the European Union. doi:10.2797/265898

Floris, F. et al., 2020. Learning analytics to evaluate the effectiveness of higher education student failure prevention. Proceedings of 17th international conference on Cognition and Exploratory Learning in the Digital Age (CELDA 2020), pp. 265-272.

Gueudet, G., 2008. Investigating the secondary-tertiary transition. Educational Studies in Mathematics, Springer Verlag, 67 (3), pp. 237-254. doi:10.1007/s10649-007-9100-6

Herridge, A. S. et al., 2020. Online Orientation among Community College Students: Academic Engagement and Sense of Belonging. Journal of Applied Research in the Community College, 27(1), pp. 17-31.

Hounsell, D. et al., 2008. The Quality of Guidance and Feedback to Students. Higher Education Research \& Development 27 (1), pp. 55-67. doi:10.1080/07294360701658765

Kai, S. et al., 2017. Predicting Student Retention from Behavior in an Online Orientation Course. International Educational Data Mining Society (EDM).

Marchisio, M. et al., 2019. Boosting up data collection and analysis to learning analytics in open online contexts: an assessment methodology. Journal of E-Learning and Knowledge Society, 15(3), pp. 79-89. doi: $10.20368 / 1971-8829 / 1135048$

Marchisio, M. et al., 2019. Start@unito: Open Online Courses for Improving Access and for Enhancing Success in Higher Education. Proceedings of the 11th International Conference on Computer Supported Education (CSEDU 2019), Vol. 1, Heraklion, Greece, pp. 639-646. doi:10.5220/0007732006390646

Marchisio, M. et al., 2020. Teaching Mathematics in Scientific Bachelor Degrees Using a Blended Approach. Proceedings of 2020 IEEE 44th Computer Software and Applications Conference (COMPSAC), Madrid, Spain, pp. 190-195. doi: 10.1109/COMPSAC48688.2020.00034

Mayhew, M. J., 2010. A Multi-Level Assessment of the Impact of Orientation Programs on Student Learning, Res High Educ 51, pp. 320-345. doi:10.1007/s11162-009-9159-2

McInerney, C. et al., 2017. Computing Camps for Girls - A First-Time Experience at the University of Limerick. In A. Tatnall \& M. Webb (A c. Di), Tomorrow's Learning: Involving Everyone. Learning with and about Technologies and Computing, Springer International Publishing, pp. 494-505. doi:10.1007/978-3-319-74310-3_50

Ocumpaugh, J. et al., 2017. Guidance counselor reports of the ASSISTments college prediction model (ACPM). Proceedings of the 7th International Learning Analytics \& Knowledge Conference (LAK '17). New York, USA, pp. 479-488. doi:10.1145/3027385.3027435

Skaniakos, T. et al., 2019. Study guidance experiences, study progress, and perceived learning outcomes of Finnish university students. European Journal of Higher Education, 9(2), pp. 203-218. doi:10.1080/21568235.2018.1475247

Sun, V. J. and Yuen, M., 2012. Career Guidance and Counseling for University Students in China, Int J Adv Counselling 34, pp. 202-210. doi:10.1007/s10447-012-9151-y 